https://doi.org/10.18593/ejj1.21184

\title{
A CONCEPÇÃO DE JÜRGEN HABERMAS SOBRE O DIREITO COSMOPOLITA: PREMISSAS FILOSÓFICAS E PRAGMÁTICAS DE UM IDEAL HUMANITÁRIO
}

\section{JÜRGEN HABERMAS'S CONCEPTION ON COSMOPOLITAN LAW: PHILOSOPHICAL AND PRAGMATIC PREMISES OF AN HUMANITARIAN IDEAL}

Teresinha Inês Teles Pires ${ }^{1}$

\begin{abstract}
Resumo: Segundo Jürgen Habermas, o direito cosmopolita deve ser compreendido como um novo paradigma do direito internacional, na perspectiva da democracia deliberativa. Explicitar as categorias discursivas e pragmáticas que justificam a posição do autor sobre o tema é o objetivo central do presente trabalho. Para tanto, as principais referências teóricas da doutrina cosmopolita são analisadas, a fim de mostrar sua importância na reelaboração do conceito de soberania nacional e na legitimação do sistema do direito internacional, como um todo. Em seguida, sugere-se uma vertente interpretativa segundo a qual o princípio do constitucionalismo republicano e a proteção dos direitos humanos constituem os principais fundamentos da democracia e do direito cosmopolita. Por último, apresenta-se um panorama da implementação do projeto, seus avanços, retrocessos e as propostas de reformas nas organizações e instituições internacionais, com ênfase no sistema das Nações Unidas. A conclusão, ao final, aponta que o modelo de democracia de Habermas é o mais compatível com as premissas da doutrina cosmopolita, constituindo ferramenta crítica para a realização do projeto na esfera institucional. $\mathrm{O}$ estudo opera com a utilização do método da pesquisa qualitativa, permeada pela análise teórico-argumentativa dos conceitos envolvidos.
\end{abstract}

Palavras-chave: Direito cosmopolita. Constitucionalismo republicano. Direitos humanos. Reformas institucionais.

\begin{abstract}
According to Jürgen Habermas, cosmopolitan law must be understood as a new paradigm of international law in the perspective of deliberative democracy. To clarify the discursive and pragmatic categories that justify the author's position on the subject is the central goal of this work. For this, the main theoretical references of cosmopolitan doctrine are analyzed, in order to show its importance in the re-elaboration of the concept of national sovereignty and in the legitimacy of international law system as a whole. Next, an interpretative strand is suggested according to which the principle of republican constitutionalism and the protection of human rights constitute the main grounds of democracy and cosmopolitan law. Finally, it is presented an overview of the implementation of the project, its advances, setbacks and proposals for reforms in international organizations and institutions, with an emphasis on the United Nations system. The conclusion, in the end, points out that Habermas's model of democracy is the most compatible with the premises of cosmopolitan doctrine, constituting a critical tool to perform the project in the institutional sphere. The study operates using the qualitative research method, permeated by theoretical-argumentative analysis of the concepts involved.
\end{abstract}

Keywords: Cosmopolitan law. Republican constitutionalism. Human rights. Institutional reforms.

Recebido em 20 de junho de 2019

Avaliado em 8 de maio de 2020 (AVALIADOR A)

Avaliado em 2 de setembro de 2020 (AVALIADOR B)

Aceito em 2 de setembro de 2020

\footnotetext{
1 Pós doutora em Direitos Humanos pela Universidade de Salamanca/Espanha. Doutora em Direito Público pelo Centro Universitário de Brasília. Mestre em Filosofia pela Universidade Federal do Rio Grande do Sul; Promotora de Justiça no Ministério Público do Distrito Federal e Territórios; Praça dos Buritis, Eixo Monumental, 70091-900, Brasília, Distrito Federal, Brasil; https://orcid.org/0000-0001-9628-1799; tes_pires@hotmail.com
} 


\section{Introdução}

Habermas é considerado, sem nenhuma divergência, um incansável defensor do estabelecimento de uma ordem institucional cosmopolita, com a criação de Órgãos internacionais nas três esferas do poder político - legislativo, judiciário e executivo - com competência para impor suas normas e decisões aos governos nacionais. O pensamento político do autor, tanto no aspecto metodológico quanto no aspecto pragmático, representa uma das principais fontes de influência, em termos de paradigma sistêmico, no que diz respeito à transformação do direito internacional, rumo ao cosmopolitismo.

A questão envolve a problemática substancial da delimitação das matérias a serem reservadas à esfera decisória de autoridades e representantes com poderes sobrepostos à autonomia dos Estados. Além disso, há que se adensar ferramentas procedimentais eficazes no desenvolvimento das capacidades de ação conferidas às instituições mundiais. Grosso modo, em assuntos de interesse geral, como, por exemplo, as questões climáticas, migratórias e de controle nuclear, a supremacia do direito mundial se justifica pela simples constatação de que decisões locais produzem efeitos em ordem planetária; em se tratando de direitos humanos, Habermas acentua o necessário intervencionismo internacional nos sistemas internos, ainda que os efeitos das decisões se restrinjam ao âmbito interno, dado o caráter universal do bem jurídico protegido. Ou seja, a proteção internacional dos direitos humanos deve alcançar padrões de legitimação mais abrangentes, aptos a promover o combate global às violações, de todas as espécies, a esses direitos, incluindo condenações e sanções pelo descumprimento das respectivas normas internacionais.

A importância do tema dispensa maiores comentários, haja vista o acirramento dos conflitos sociais, de Norte a Sul, com viés agressivo e intolerante, em relação às minorias étnicas e religiosas, e o avanço da dominação hegemônica dos interesses das superpotências, com graves retrocessos, sobretudo, econômicos na condição de vida dos países periféricos. $\bigcirc$ mundo assiste, com perplexidade, a um cenário de disputa de poderes, inclusive, no âmbito da condução das políticas e decisões jurídicas das instituições internacionais. Em tal cenário, é imprescindível a mudança de mentalidade do sistema do direito internacional, como um todo, a fim de imprimir uma dinâmica multipolar nos processos de decisão, em benefício da distribuição igualitária dos recursos naturais, em situação de escassez.

O trabalho tem por escopo empreender uma leitura da teoria habermasiana à luz do modelo do republicanismo mundial, que constitui, na atualidade, a tônica da transnacionalização do direito. Como se pretende demonstrar, a perspectiva do ordenamento cosmopolita, adensada por Habermas, delineia passos firmes na direção de uma governança voltada para o bem-estar de todos os povos, alicerçada na cooperação - multinível - entre países ricos e pobres, e não na manutenção subliminar de uma globalismo imperialista com vestes democráticas. Diante das tendências à exacerbação do absolutismo nacionalista, o desafio posto é o da defesa do Estado de Direito cosmopolita, 
harmonicamente, estruturado, com a criação de instituições jurídicas e políticas cujas decisões sejam dotadas de eficácia vinculante no controle das decisões dos Estados nacionais.

$\mathrm{Na}$ visão de Habermas, vivencia-se, na atualidade, uma tensão entre nacionalismo e republicanismo, agravada pela prevalência crescente dos interesses do mercado financeiro mundial na produção econômica dos países democráticos, com o consequente desmonte do Estado social e das fontes de arrecadação. Tudo isso impõe a reformulação dos limites do poder estatal, de modo a superar os padrões não intervencionistas do direito internacional, tradicionalmente, incorporados à teoria política da modernidade $\mathrm{A}$ solução do impasse reside no fortalecimento das instituições internacionais capazes de agir, no tocante às matérias de sua legítima competência, e na edificação de uma sociedade civil capaz de transitar em esfera global.

A investigação tem por fio condutor o método de pesquisa qualitativa, visando explicitar as particularidades teóricas e práticas envolvidas na construção do fenômeno da democracia pósnacionalista, na compreensão de Habermas e de autores, que com ele dialogam, em torno do projeto cosmopolita. Sem pretensões, portanto, de se chegar a resultados definitivos, intenta-se contribuir para o debate, hoje emergente, na dogmática do direito internacional, acerca dos valores e metas inseridos no desenvolvimento progressivo do sistema. Importante esclarecer que a investigação parte de uma posição, subjetivamente, convicta, a favor da cosmopolitização do direito e das reformas propostas para sua implementação.

O artigo está dividido em três seções: a primeira se ocupa da passagem da doutrina do cosmopolitismo moral ao cosmopolitismo democrático e jurídico, a fim de explanar a base originária do pensamento de Habermas relativo ao tema; a segunda seção discute a conexão existente entre o princípio republicano e o protagonismo dos direitos humanos, que permeia o paradigma de uma sociedade democrática cosmopolita; a terceira seção, por fim, atém-se aos fundamentos utilizados pelo autor na criação de um modelo institucional, capaz de concretizar as premissas de uma comunidade cosmopolita no século XXI.

\section{As vertentes dogmáticas do cosmopolitismo na moral, na política e no direito: fio condutor para a reconstrução da ideia de Nação na perspectiva global}

A doutrina do cosmopolitismo democrático tem sua origem no pensamento grego, quando se enunciou a ideia de uma identidade cidadã de dimensão global. Martha Nussbaum é quem melhor elucida a historicidade clássica do conceito de "cidadão do mundo". A expressão foi utilizada, pela primeira vez, pelo filósofo cínico Diógenes, no século IV antes de Cristo, e adotada, posteriormente, por seus seguidores estoicos, destacando-se Cícero e Sêneca. Por cidadão do mundo, ou cosmopolita, compreende-se, desde então, a pessoa que se considera comprometida com "toda a comunidade de seres humanos", não definindo sua identidade, essencialmente, a partir de referências territoriais ou de sentimentos de pertença a determinados grupos e etnias (NUSSBAUM, 1999, p. 14, 17). Após a 
entrada da era cristã, a filosofia estoica manteve importante influência na evolução do pensamento filosófico. Com efeito, a doutrina escolástica de Santo Agostinho e Tomás de Aquino reafirmou os valores estoicos humanitários, tais como o valor universal da dignidade da humana e da coexistência pacífica, incorporando, no debate político da época, a concepção de uma cidadania mundial (CID, 2011, p. 187).

Assim, desde os seus primórdios, os estereótipos do orgulho nacionalista ou patriótico não encontraram eco exclusivo na formação da identidade político-cidadã. $O$ indivíduo foi levado a autocompreender-se como sujeito cultural universal, para além de sua projeção no contexto de sua comunidade local. Isso nunca teve por corolário a contraposição às identidades nacionais; da mesma forma, falar de uma cidadania cosmopolita não interfere na seara de outras espécies de identidade coletiva, como, por exemplo, a identidade de gênero, a de credo religioso ou a dos grupamentos afetivos-familiares. Trata-se, simplesmente, de ampliar o horizonte da interação societária, impingindo na consciência de cada um o sentido moral da inclusão, sendo qualquer pessoa, ou grupo, merecedora do mesmo reconhecimento, por compartilhar a mesma essência humana, que a todos unifica em torno de um interesse e de um destino comum (NUSSBAUM, 1999, p. 20).

$\mathrm{Na}$ modernidade, o ideal cosmopolita transpõe-se do terreno abstrato da moral para a política e o direito, a partir da filosofia kantiana da história universal da humanidade. Kant, o filósofo do transcendentalismo apriorístico, volta-se para a história, para o reino empírico da relação entre os povos, movido por uma preocupação com o estado de guerra, sempre favorável às conquistas dos países fortes, militarmente, em detrimento da capacidade dos fracos na defesa de suas fronteiras. ${ }^{2}$ Preocupou-se Kant, nessa etapa dos seus escritos, com a "paz perpétua", com o equilíbrio de forças entre as nações; além disso, o filósofo voltou o seu olhar para a justiça e, portanto, para o valor da dignidade humana, na acepção igualitária do termo. Propôs, assim, um modelo de confederação entre os Estados-Nação, que se tornou o marco originário da doutrina do cosmopolitismo jurídico.

Pois bem. Em que consiste o projeto cosmopolita de Kant? Resgatando a categoria política grega da "cidadania mundial", o autor vislumbra o propósito idealizado de uma história universal como realização da perfeita disposição natural do "gênero humano" (KANT, 1988b, p. 35). Da perspectiva da história, Kant é levado, então, à esfera do direito, em que defende, em vista da paz mundial, que todos os Estados devem promulgar uma Constituição republicana. As Constituições nacionais, em tal escala de valores, seriam imprescindíveis para o estabelecimento de uma "federação de estados livres" (KANT, 1988a, p. 127, 132).

\footnotetext{
2 É preciso esclarecer que Kant, em seus textos políticos, mantém "em certo sentido um fio condutor a priori" (KANT, 1988b, p. 37) Obviamente, tratando-se de um pensamento sistêmico, a base metodológica da filosofia transcendental de Kant está pressuposta em todo o seu arcabouço fundante, desde a teoria do conhecimento, passando pela moral, até a política e o direito. Com a ferramenta conceitual da cidadania mundial, Kant, em rigor, adicionou à sua categoria moral do "Reino dos Fins" uma configuração concreta, materializada na esfera das relações sociais mundiais, na qualidade de um modelo de entendimento mútuo, em nível universal. Sobre o princípio do Reino dos Fins, remete-se o leitor às obras do próprio filósofo (KANT, 1989, 2009). Consulte-se, ainda, a obra da autora: Pires (2012).
} 
A partir daí, Kant dimensiona sua compreensão no sentido da existência de três esferas do ordenamento jurídico - os sistemas nacionais, o interestatal e o cosmopolita. $\bigcirc$ último envolve as relações diretas entre os cidadãos mundiais e as instituições ou organizações globais. Dessa abordagem do ordenamento cosmopolita advém os fundamentos doutrinários do cosmopolitismo democrático, gestado e desenvolvido nos séculos XX e XXI. Os autores contemporâneos, regra geral, partem de Kant, por entenderem que ele construiu uma nova concepção, segundo a qual o cosmopolitismo não poderia tornar-se um projeto realizável, sem se sedimentar em estruturas institucionais. Contudo, Kant restringiu a validade do direito cosmopolita ao âmbito da regulamentação das "condições de hospitalidade universal", ou seja, ao direito de visita a território estrangeiro (KANT, 1988a, p. 137-138). ${ }^{3}$

Esse enquadramento limitado da esfera cosmopolita perdeu sua atualidade, conduzindo o retorno à doutrina em novas bases justificatórias. A centralidade kantiana das relações internacionais na segunda esfera do sistema, a do direito interestatal, deixou de ser suficiente para a defesa de uma cidadania mundial. A preocupação de Kant, em seu tempo, com a dominância hegemônica dos países desenvolvidos, todos no continente europeu, em relação aos países desprotegidos, foi apaziguada pela proposta de uma Confederação de Estados, que lhe pareceu adequada ao propósito da paz mundial; porém, a problemática enfrentada, na atualidade, adquire outras proporções. O tempo presente é o da hegemonia do capitalismo financeiro, com forte penetração na comunidade internacional, inclusive, na dinâmica decisória dos sistemas de proteção aos direitos universais do ser humano.

Após a Declaração Universal dos Direitos Humanos, de 1948, assiste-se à "transição do direito internacional", na concepção tradicional, para uma nova moldura institucional, de maior consistência normativa, pautada no paradigma de uma justiça cosmopolita. Nesse processo, desencadeia-se uma mudança de rumo nas relações entre os Estados com o direito internacional, do ponto de vista do exercício da soberania (BENHABIB, 2006, p. 15-17). O modelo do Estado soberano e o princípio da autodeterminação dos povos, tal como edificado pelo contratualismo de Locke e Rousseau, já não encontra o mesmo nível de estabilidade. Consequentemente, a mera união cooperativa dos Estados, sem a criação de instituições jurídicas e políticas de âmbito mundial, com competência para coibir, efetivamente, as ameaças à paz e outras violações aos direitos humanos, não é capaz de levar ao resultado pretendido pelo projeto cosmopolita.

Desde Kelsen, o dogma da soberania absoluta é posto enquanto uma etapa, na teoria do Estado, a ser superada. Contrapõe-se o jus-filósofo àqueles para quem o Estado e o direito, o Estado e a "sociedade política", são, em essência, a mesma coisa, não havendo outras esferas com as quais os indivíduos estejam, subjetivamente, vinculados, em sua condição de cidadãos. Kelsen é um crítico da tese, defendida por Umberto Campagnolo, de que o Estado nacional representa o único

\footnotetext{
3 Ainda sobre o projeto kantiano de uma sociedade cosmopolita e sua reinserção no debate contemporâneo, no que diz respeito à formação pós-nacional do Estado de Direito, consulte-se Cid (2011, p. 187-188), Deleixhe (2014), passim; Habermas (2016, p. 161-219) e Menezes (2017, p. 23-52).
} 
ordenamento político, para além do qual a "consciência do cidadão" a ele pertencente não alcança nenhuma percepção. Tal maneira de pensar, para Kelsen, não passa de uma formulação alternativa para o "dogma totalitário" da soberania; a tese censurada conduzira, assim, à completa rejeição à vigência do direito internacional, salvo na condição de um braço do direito estatal. Na verdade, acentua o jurista, o direito internacional unifica os sistemas jurídicos nacionais, sob uma juridicidade única, a delegar competências, ou esferas de poder, a todos os ordenamentos dos Estados. Quer dizer, ao contrário de ser um apêndice do direito estatal, o direito internacional tem precedência originária, pois é de sua alçada estabelecer os limites das competências dos Estados (KELSEN; CAMPAGNOLO, 2002, p. 119-123, 129-132).

Assim como em Kant, não há, no pensamento de Kelsen, a sugestão da implementação de um Estado federativo global, que configure o espaço coercitivo do direito internacional. Seu desenvolvimento, diferentemente, deve dar-se sob a figura de uma ordem jurídica mundial sem Estado. O direito não se confunde com o Estado, por isso, é possível construir um projeto de união cidadã, destinado a limitar a soberania dos Estados, através de etapas sucessivas de afirmação da primazia do direito internacional, até chegar ao modelo aprimorado do direito cosmopolita. Dizse aprimorado, porque seria essa a etapa a sedimentar um elo direto entre os cidadãos mundiais com a institucionalização de um direito globalizado, com o que, opondo-se à tese de Campagnolo, se efetivaria a identificação, subjetivamente, compartilhada com uma ordem jurídica sobreposta à ordem dos Estados-Nação. Em outras palavras, a perspectiva de uma identidade cidadã, nesses moldes, se construiria a partir da autocompreensão dos indivíduos enquanto sujeitos de direitos e deveres em dimensão universal, independentemente de sua associação aos seus Estados.

Como já dito, a mundialização democrática não significa a eliminação do Estado-Nação e, portanto, da soberania nacional; busca-se, apenas, limitar os poderes soberanos, no tocante a decisões pertinentes a tópicos específicos, relacionados aos direitos humanos, ao meio ambiente e ao controle nuclear, dentre outros assuntos da mesma abrangência. A dimensão ideal da soberania, na esteira de Kelsen, é a do compartilhamento entre as competências atribuídas aos três níveis de decisão local, regional e global. Trata-se de um sistema político-jurídico "híbrido", no qual se estabelece a interdependência entre governos soberanos e "estruturas plurais de autoridade", operacionalizada sob a égide de normas fundamentais de vinculação universal (HELD, 1991, p. 150-151, 155, 157).

Juntando-se àqueles que defendem a reformulação do conceito de soberania, Habermas adentra no estudo do cosmopolitismo. Inicialmente, dedica maior atenção ao tema em seu livro "A Constelação Pós-Nacional", lançado no ano de 1998. Nesse estágio do seu pensamento, o autor lança sua crítica a dois aspectos, derivados da predominância moderna da corrente nacionalista nas relações geopolíticas, continentais e intercontinentais: primeiro, salienta-se os perigos da homogeneidade cultural, que, sempre, resulta na extinção gradual das identidades minoritárias; segundo, põe-se em foco o avanço das políticas neoliberais no mundo ocidental e a consequente ruptura com o 
Estado de Bem-Estar-Social europeu, o que conduziu a humanidade a patamares insustentáveis de estratificação socioeconômica.

Com espeque nesses dois problemas - homogeneidade cultural e neoliberalismo, deletérios para as bandeiras cosmopolitas da coexistência pacífica e da justiça social, Habermas chega à conclusão de que a transnacionalização da política e do direito, no plano institucional, é a única via capaz de reverter o avanço de uma verdadeira catástrofe social, pois, somente, assim, os Estados podem aderir ao comprometimento obrigatório com ações cooperativas, em benefício das comunidades em estado de vulnerabilidade (HABERMAS, 2001, p. 66, 69, 72-3). ${ }^{4}$

Em relação à diversidade cultural, pincele-se a influência referencial da doutrina do cosmopolitismo moral, grego-cristão, em sua incitação à mudança de mentalidade, individual e/ou coletiva, em particular, no tocante aos consectários da cidadania, em sentido amplo. Nos tempos atuais, essa intencionalidade encontra campo propício de evolução, em face da irreversibilidade do multiculturalismo, que não se assenta, somente, na divisão de fronteiras nacionais; regra geral, o ambiente cultural interno de cada país já é marcado pela coexistência de diversas etnias e formações moral e/ou religiosa. Como explica Stuart Hall, o sujeito da pós-modernidade não possui mais uma identidade fixa, e sim fragmentada. Nele coexistem múltiplas identidades, que, inclusive, se transformam, "continuamente", de acordo com os rumos da história do seu tempo. Com o fenômeno da globalização, as "identidades culturais" também se tornam mutantes e descentradas (HALL, 2002, p. 12-14, 23).

Em contraposição ao processo de homogeneização cultural, Habermas introduz sua visão do que denomina "patriotismo constitucional. Essa ideia sugere a substituição do conceito de nação enquanto unidade cultural por um conceito "de uma nação de cidadãos." A proposta vai no sentido da concepção de uma democracia pluralista, fundada em uma "identidade pós-nacional", ou seja, em "liames identitários" inclusivos, construídos pela via dos direitos de participação política nas deliberações democráticas, sem a mediação de "características etnoculturais." (BUNCHAFT, 2015, p. 30-31, 36). Em tempos de globalização, a noção de cidadania não se coaduna com uma identidade étnica específica, e a insistência retrógrada no unilateralismo social do Estado Nação não conduz a outro caminho senão o da "limpeza étnica" (HABERMAS, 1998, p. 137).

Somadas a essas novas estruturas de identidade coletiva, as disparidades sociais deram origem ao problema das correntes migratórias. De sociedades coesas e homogêneas, do ponto de vista

\footnotetext{
4 Ver, também, do mesmo autor, Era das Transições (HABERMAS, 2003, p. 40-47). Nessa obra, enfatiza-se a urgência da edificação de "uma ordem cosmopolita juridificada, em vista da superação das guerras travadas entre países soberanos, como, por exemplo, a guerra do Golfo, caracterizada por um evidente propósito de limpeza étnica, em relação aos refugiados de Kosovo. Em casos assim, como defende Habermas, não há de prevalecer a proibição da intromissão internacional na soberania dos Estados, intromissão que deve ser compreendida em sentido positivo, enquanto 'missão para a obtenção da paz'." Dentre outros conflitos étnicos comandados sob a batuta de Estados autoritários, ocorridos antes do estado de terror em Kosovo, Habermas menciona as guerras da Somália, Ruanda e Bósnia.

5 Conforme Bunchaft (2015, p. 34), Habermas "desenvolveu o conceito de patriotismo constitucional como uma nova maneira de fornecer um modelo de identificação política capaz de superar o nacionalismo, concebendo a identidade nacional alemã de forma diversa da compreensão neo-historicista alemã." Ver, também, sobre o conceito em referência, Lacroix (2005, p. 123-131) e Menezes (2017, p. 106-110).
} 
étnico, cultural e religioso, elas se tornaram, ao contrário, sociedades heterogêneas e multiculturais. A suposta "uniformidade", imanente ao conceito do Estado-Nação, restou, assim, fragmentada, como bem explicita Hall. Além disso, o apelo à globalização econômica e a forte concorrência entre as "corporações multinacionais" financeiras produziram graves sequelas nos processos de autodeterminação democrática (HABERMAS, 2001, p. 99-100).

Os questionamentos de Habermas com relação aos conflitos redistributivos prosseguem, ainda, mais enfaticamente, a partir da virada para o século XXI, momento em que ele assume posição de enfrentamento às formas dominantes do capitalismo monetário, defendendo o resgate da função prática dos discursos utópicos igualitaristas. $\bigcirc$ pensamento utópico adiciona à dimensão histórica um potencial de ação necessário ao fortalecimento dos movimentos sociais, à exposição dos antagonismos de classe e, por fim, à reinvenção do Estado de Bem-Estar Social. Sabe-se que Habermas é fortemente influenciado pela análise marxista do sistema capitalista de produção, mas não assume viés revolucionário, tentando, ao contrário, vislumbrar a possível conciliação entre o capitalismo e a democracia; é, exatamente, essa a característica central do modelo da democracia do Estado de Bem-Estar - padrão satisfatório de igualdade social sem modificação na relação capital e trabalho. Na visão de Habermas, os acentos utópicos da modernidade se deslocaram "do conceito de trabalho para o de comunicação", sendo a esfera pública o local onde se desenvolve a "confrontação política." (HABERMAS, 2015, p. 121, 210-211, 218-220, 237).

Após a exposição das vertentes da doutrina do cosmopolitismo, do debate desenvolvido ao longo da história da filosofia política, sobre o tema, e de como seus conceitos fundamentais se projetaram na análise jurídica do estatuto de validade do direito internacional, se irá, na seção seguinte, adentrar, com mais profundidade, na teoria de Habermas. Intenciona-se, sobretudo, elucidar o elo de ligação do seu modelo de racionalidade com o ideal do direito cosmopolita, o que se consolida pela adesão ao princípio republicano e ao protagonismo dos direitos humanos.

\section{0 primado da universalidade inclusiva dos direitos humanos na construção de uma república cosmopolita}

O ideal habermasiano da solidariedade universal e de um constitucionalismo inclusivo foi sedimentado em sua teoria do agir comunicativo, alicerçada no método da racionalidade pragmática, cuja finalidade é a busca do entendimento intersubjetivo de todos os envolvidos, com vistas ao consenso. Exige-se, para que o consenso seja um consenso democrático, a consideração da totalidade das pretensões de validade apresentadas pelos participantes da ação comunicativa. Por conseguinte, a interação de sujeitos capazes de apresentar razões justificadoras de suas pretensões, estando todas elas sujeitas a críticas e processos argumentativos de reconhecimento público, deve ser orientada 
pelo significado societário das situações de vida, e coordenada pelo interesse na autocompreensão comunitária (HABERMAS, 1987, p. 27, 31-32). ${ }^{6}$

Assim, o sentido da inclusão da alteridade, ou seja, da igualdade comunicativa, na consideração das demandas por reconhecimento de direitos, está, naturalmente, incorporado ao propósito da razão "pragmática universal", 7 através do estabelecimento de condições procedimentais de formação da vontade e da opinião pública. Para que o consenso político cumpra tais condições, reitere-se, é necessário assegurar a efetiva participação de todos e a igual oportunidade na formulação de pretensões, o que se materializa, na esfera pública, no debate político, aberto aos diversos grupos, associações e entidades representativas dos interesses sociais. Clarifica-se, nesse padrão, a historicidade pós-metafísica da ação comunicativa, que implica a rejeição ao sujeito transcendental, não empírico, de Kant.

A maior preocupação de Habermas, a perpassar toda sua produção intelectual, consiste em aprofundar o conceito de democracia. Na obra dedicada à teoria democrática e ao direito o autor destrincha, inicialmente, a compreensão da tensão - validade e facticidade - existente no direito, do ponto de vista interno, e, em um segundo momento, analisa essa mesma tensão no âmbito da relação entre o direito e a política. Para Habermas, a "política deliberativa" tem protagonismo na concretização da democracia, com o que o autor vislumbra um possível entendimento discursivo que vá além dos interesses pessoais dos seus atores, superando o padrão do liberalismo e colocando em perspectiva o "discurso da justiça". A teoria do discurso é, notavelmente, marcada pelo republicanismo e pela centralidade do Estado de Direito de perfil pluralista (HABERMAS, 2010, p. 10, 18-21).

Os mecanismos de fortalecimento das esferas de manifestação da sociedade civil, sobretudo, de suas camadas periféricas, constitui fator de extrema importância no desenvolvimento do processo democrático. A distribuição desigual das capacidades comunicativas, no seio de sociedades fragmentadas, e a impotência das classes sociais periféricas, no sentido de contribuírem para as escolhas políticas, denotam um déficit democrático, observável na maioria das comunidades. A esfera pública, segundo Habermas, deve "estabilizar-se por si mesma", na prática comunicativa, representando a instância própria para o aprimoramento do "sistema político como um Estado de Direito." (HABERMAS, 2010, p. 58, 82, 103, 106).

A visão da esfera pública, que Habermas apresentou em suas considerações sobre democracia, política e direito, enfatiza a importância da institucionalização dos canais de participação da sociedade

\footnotetext{
6 Não é possível, aqui, aprofundar a abordagem da teoria do discurso de Habermas, com o que remetemos o leitor à leitura de sua obra magistral, Teoria do Agir Comunicativo, destacando, em especial, a Introdução (Tomo 1), onde se explicitam os conceitos fundamentais da problemática da racionalidade no novo paradigma do discurso, seja do ponto de vista da hermenêutica filosófica, seja da perspectiva da sociologia.

7 Saliente-se que Habermas usa o termo "pragmática universal" com o significado atribuído pela teoria dos atos de fala, de John Austin, segundo a qual toda comunicação mediatizada pela linguagem não possui apenas conteúdos fonéticos ou semânticos universais, mas também elementos pragmáticos, em si mesmos, passíveis de universalização. Toda interação linguística é também uma ação, um "ato ilocucionário", por conter uma intenção de convencer ou conduzir a uma decisão. Parte dessa abordagem o princípio do discurso de Habermas, que, em sua aplicação à política e ao direito, impõe a todos, na busca do consenso intersubjetivo, a observância das condições ideais de fala, com vistas ao entendimento mútuo, sendo esse o fio condutor do processo de universalização das pretensões de validade. Sobre a teoria dos atos de fala, consulte-se Austin (1965); sobre o princípio do discurso, consulte-se Habermas (1990, p. 77-78, 102-103, 1987, p. 23-58).
} 
civil. A esfera pública, e nisso Habermas vai além de Hanna Arendt, torna-se efetiva quando é transposta para os Órgãos decisórios, já que, somente assim, se abre aos cidadãos o poder de interferir na formação da opinião e da vontade. Esse aparato teórico vai ao encontro do projeto de uma sociedade global, sustentado na formação de vínculos diretos entre cidadãos de todas as partes do mundo e instituições internacionais. A criação, por exemplo, de um Parlamento mundial, do qual se voltará a falar adiante, parte do princípio de que ao cidadão se deve permitir uma esfera de participação efetiva nas decisões internacionais, através do voto em representantes, periodicamente, eleitos.

A utopia igualitária, a mover as intenções favoráveis à uma democracia cosmopolita "juridificada", é desenvolvida, com maior afinco, por Habermas, em seu livro "A inclusão do outro", um dos textos mais influentes na dimensão da fundação de poderes institucionais supranacionais. $\bigcirc$ princípio originário da argumentação é o da solidariedade universal, que perpassa o debate filosófico e jurídico sobre o cosmopolitismo. Solidariedade universal significa, na concepção dos direitos humanos, a constituição de um sistema de cooperação internacional entre os povos, na resolução dos problemas afetos à garantia de uma vida digna, com o atendimento das necessidades básicas de todos. Logo se vê a inserção dessa demanda em um contexto que ultrapassa os restritos parâmetros das soberanias nacionais.

Há, ainda, uma clara tensão entre o ideal de uma comunidade jurídica igualitária e o "particularismo" veiculado por visões nacionalistas. É preciso encontrar um ponto de equilíbrio, evitando a polarização do debate. $\bigcirc$ apego incondicional às estruturas internas dos governos estatais abre margem a processos políticos locais arbitrários, na contramão dos "princípios republicanos". Aqui volta-se à ênfase de Habermas na crítica às doutrinas nacionalistas, distanciadas da realidade social. A saída para essa problemática está na conexão entre o núcleo cosmopolita da cidadania ao gozo efetivo dos direitos humanos, não, apenas, os individuais e políticos, mas, no mesmo patamar, os direitos sociais e culturais. Em suma, não se pode conceber a soberania nacional fora do paradigma dos direitos humanos (HABERMAS, 1998, p. 116-118, 137).

As categorias morais e políticas se inter-relacionam na interpretação de Habermas sobre a democracia cosmopolita. Da contextualização do nacionalismo, em novas premissas, chega-se, como se falou antes, ao resgate da doutrina republicana, como contraponto às tradições etnocêntricas, o que fornece razões suficientes ao protagonismo discursivo dos direitos humanos.

A essência de uma república está na promoção do bem comum. Governos republicanos não governam para o benefício de suas autoridades, ou para o benefício de poucos, mas para o interesse de toda a comunidade, pobres, classe média e ricos. À luz da filosofia política de Aristóteles, quando se fala em democracia republicana, se está vislumbrando um regime de governo que atenda às demandas plurais dos diversos setores da sociedade. É esse, também, o sentido em que foi construído por Rousseau o conceito moderno de soberania popular. Em seguida, nas sociedades industrias, a passagem da teoria democrática clássica para o constitucionalismo, com o apogeu da supremacia das liberdades e da "igualdade de condições", revigorou o republicanismo. Desde a narrativa de 
Tocqueville, a "aceitação da mobilidade social" e o próprio "conflito social" tornaram-se os motores simbólicos da ação democrática, indissociáveis do valor "político-moral" da igualdade (ARAÚJO, 2013, p. 9, 120, 179, 194, 287-288, 293).

Esse arcabouço conceitual serviu de alicerce para a metodologia procedimentalista de Habermas, segundo a qual a unificação de uma comunidade cidadã não decorre de uma identidade "pré-política", étnica, cultural ou de "uma língua comum", mas do "respeito por um procedimento de formação democrática da vontade e da opinião", como determinado na Constituição. Habermas insiste em rejeitar o enraizamento da cidadania na "identidade nacional de um povo." Uma "cultura política comum", em sociedades multiculturais, caracteriza-se, muito mais, pelo reconhecimento da pluralidade e pelo interesse na integração das múltiplas visões morais e políticas que formam o tecido social da comunidade (LACROIX, 2005, p. 132-133).

A teoria democrática de Habermas conserva premissas fundamentais do liberalismo de Locke, em especial, a valorização da autonomia individual e dos direitos subjetivos. O próprio primado dos direitos humanos é um corolário do modelo liberal, porque traz à lume a necessidade do combate às "maiorias tirânicas", que podem dominar o terreno das democracias nacionalistas. De outro lado, a concepção de Habermas da autonomia é, acentuadamente, republicana. Sua ênfase na autonomia pública, compreendida enquanto liberdade de participação na formação da vontade política, não deixa dúvidas sobre esse ponto. Autonomia privada e autonomia pública se complementam na estruturação de uma democracia constitucional. No entanto, a capacidade da "auto-organização dos cidadãos" é a ferramenta principal, que dá o tom inclusivo da democracia deliberativa, como pensada por Habermas (OLIVEIRA, 2017, p. 282-284). É nesse sentido que a linguagem dos direitos humanos, a despeito de sua conotação liberal, é marcada pelo ideal republicano. Aliás, arrisca-se postular, a igual importância dos direitos sociais e econômicos, em comparação aos direitos individuais, tão cara a Habermas, só adquire sustentação sólida a partir de uma fundamentação republicana.

Transpondo esse paradigma para o âmbito das relações interestatais e do direito cosmopolita, pode-se dizer que um sistema híbrido, que vincula a soberania a uma normatividade universal, centralizada nos direitos humanos, somente, é sustentável a partir de um constitucionalismo de perfil republicano. Em princípio, os direitos humanos são justificáveis, com fundamento em argumentos morais, e isso se explicita tanto no cosmopolitismo moral quanto no democrático. No entanto, como acentuado por Habermas, os direitos humanos foram introduzidos no cenário internacional na qualidade de lei positivada, indo, portanto, além do âmbito moral; seu estatuto jurídico constitui o âmago do projeto de uma sociedade mundial republicana e de um novo Estado de Direito, sobreposto aos limites do Estado Nação. O direito cosmopolita ressurge, assim, como uma "consequência lógica" da constituição do Estado de Direito (HABERMAS, 1998, p. 182-183).

Desse modo, Habermas, adere, explicitamente, ao propósito cosmopolita, e reafirma a necessidade de se estender os canais de participação direta dos cidadãos no processo democrático, sem a representação de seus governantes. $\bigcirc$ caminho a seguir, Habermas propõe, em uníssono, com 
os demais defensores do direito cosmopolita, começa com o fortalecimento da atuação das Nações Unidas, criando novos organismos decisórios, em especial, uma Assembleia popular global. A partir desse degrau, pode-se projetar um constitucionalismo estatal, vinculado a uma república mundial, intersubjetivamente, legitimado e capaz tornar efetiva a solidariedade universal (HABERMAS, 1998, p. 186-187, 137-138). Afinal, se os direitos humanos são constitutivos da democracia, de nada adianta, apenas, seu reconhecimento formal por parte dos Estados, ao ratificarem documentos e declarações da ONU. Se os direitos humanos não são respeitados em seus territórios, só resta aos cidadãos recorrer às vias abertas à sua participação no funcionamento das instituições internacionais.

Nesse particular, Seyla Benhabib, influenciada pelas ideias habermasianas, aprofunda a tensão existente entre a autodeterminação soberana e os direitos humanos, além de conclamar os Estados a assumirem sua responsabilidade na democratização das instâncias do direito internacional; e a transmutarem sua visão da cidadania, no sentido plural da pós-nacionalidade. $O$ indivíduo não é cidadão de um único corpo político, mas de vários, podendo exercer, ao mesmo tempo, suas prerrogativas perante distintas "entidades", desde a sua comunidade política local até a "sociedade civil global”. O ponto de coesão entre as múltiplas esferas da cidadania reside, na esteira de Kant, no modelo do Estado republicano, que deve moldurar as constituições nacionais. Mais uma vez, não se está no terreno de qualquer concepção de soberania; a interpretação pós-nacional da soberania deve atender o princípio republicano, que exige, não, apenas, a fundação da ordem constitucional, mas, também, sua "conformidade" aos padrões "universais dos direitos humanos." (BENHABIB, 2006, p. 21, 32).

Nessa visão, a delimitação do conteúdo dos direitos humanos não está à disposição dos critérios interpretativos das competências dos governos locais, sob pena de desconstrução da validade do sistema como um todo. Como se discutirá na próxima seção, somente um "poder executivo forte", no nível mundial, ao qual se reserve atribuição para limitar o poder soberano dos Estados, o que ainda não existe, pode assegurar a concretização da Declaração de Direitos da ONU. A rigor, o momento atual é sensível, já que se vive, inclusive, uma regressão à visão nacionalista, dificultando a transição do direito internacional para o direito cosmopolita. Não se trata de estabelecer uma disputa por espaço normativo, entre nações soberanas e normatividade mundial, mas, antes, de uma interação estruturada por um ordenamento jurídico organizado em escala planetária. Falar em legalidade, na esfera dos direitos humanos, significa postular a supremacia vinculante do ordenamento do direito cosmopolita sobre a soberania dos Estados (HABERMAS, 1998, p. 191-193, 199).

\section{A implementação institucional da comunidade cosmopolita no século XXI}

No seu estágio atual de desenvolvimento, a relativa incapacidade do projeto da mundialização do direito, de se materializar como um modelo substitutivo, em relação ao modelo do Estado-Nação, produz uma crise reveladora de um vazio institucional. $O$ direito interestatal já não consegue se manter, nos mesmos parâmetros de efetividade, em face do esfacelamento do 
modelo nacionalista; de outro lado, o modelo cosmopolita ainda não se solidificou suficientemente. Quais os passos, ainda, precisam ser percorridos? Como enfatiza Delmas-Marty, deve-se ter em mente que a simples transferência parcial de legitimidade decisória, por parte dos Estados-Membros, às organizações internacionais não resolve o problema; é necessário ir além, criando, de início, mecanismos para conceder poderes participativos aos cidadãos e às organizações não institucionais, consideradas, pela jurista, os "novos autores da mundialização." Assim, se vislumbra um equilíbrio de forças entre os diversos agentes "econômicos e civis." (DELMAS-MARTY, 2007, p. 7-8, 23, 33-34).

O diálogo multilateral, para progredir, depende da receptividade do direito internacional perante os governos e sociedades nacionais. $\bigcirc$ entendimento comum, no sentido da criação de estruturas jurídicas que fixem competências decisórias às instâncias transnacionais, exige desprendimento, por parte das autoridades locais, do absolutismo normativo do direito interno. Em regra, a conjugação das esferas plurais de competência não se desenvolve, facilmente, sem a edificação de um sistema de "controle internacional", ou seja, sem a juridificação, ou positivação expansiva, do direito internacional. $\bigcirc$ multilateralismo dos poderes, diga-se de passagem, alcançou maior grau de aceitação espontânea nos países europeus, onde os juízes, principalmente, se mostram muito "influenciados pelo direito internacional." (DELMAS-MARTY, 2007, p. 43, 45, 50).

Para implementar a democracia cosmopolita, várias propostas de reformas nos Órgãos de direito internacional foram postas em discussão. $\bigcirc$ "pivô" da transformação do seu sistema, como um todo, concentra-se na democratização da Organização das Nações Unidas. O objetivo maior da mudança de paradigma pretendida é equilibrar a distribuição dos benefícios e do alcance da autodeterminação dos povos, eliminando focos de dominação imperial, através da guerra ou da ingerência política nos países oprimidos. Para que isso se viabilize, impõe-se a ampliação das "funções" das organizações internacionais e a solidificação de sua legitimidade, aperfeiçoando-se, assim, as ferramentas mundiais da democracia; além disso, deve-se substituir o uso da força militar pela ação humanitária, com espeque nos princípios da "não violência" e da igualdade política (ARCHIBUGI, 2008, p. 156, 277-779, 281).

A Carta das Nações Unidas, de 1945, traz para o direito internacional deveres, antes, conferidos, apenas, aos Estados nacionais; já no seu Artigo 1, n⿳ 1 e 3, afirma-se a meta sistêmica da paz mundial e da garantia aos direitos humanos, obrigações estas que preenchem, cada vez mais, a agenda do Conselho de Segurança. Nas últimas décadas, as hipóteses de ameaça, ou rupturas, à paze à "segurança internacional" foram estendidas, em grau significativo. Da mesma maneira, alargou-se a enumeração dos riscos ao meio ambiente e à marginalização das populações entregues à pobreza e às epidemias (HABERMAS, 2007, p. 375).

Em contrapartida, é inegável a constatação de que o Conselho de Segurança da ONU vem atuando com dois pesos e duas medidas, ao conferir, com frequência, "tratamento desigual" a casos semelhantes. Como exemplo dessa realidade, mencione-se a rápida ação do citado Órgão, em resposta os ataques de 11 de setembro de 2001, em comparação ao interesse em solucionar o conflito genocida 
ocorrido em Ruanda, no ano de 1994, que ocasionou muito maior número de mortes, sem medidas efetivas para coibir o massacre. Tal disparidade de ação foi destacada em um relatório entregue às autoridades competentes, em 1 de dezembro de 2004, pela "comissão encarregada da reforma" da ONU, sob o título "Ameaças, Desafios e Mudanças", que foi utilizado pelo então Secretário Geral, Kofi Annan, em seu discurso sobre o tema, proferido em 3 de maio de 2005 (HABERMAS, 2007, p. 374, 377).

Em rigor, a ONU é o único agente supranacional não estatal no cenário geopolítico mundial, cujo empenho, em termos práticos, se resume a duas funções: "preservar a segurança internacional" e proteger os direitos humanos. O crescimento da Organização é notável; só na segunda metade do século XX, passou de "51 para 192" Estados-membros. Ademais, os Estados encontram-se sob pressão cada vez maior, no sentido do cumprimento das normas de direito internacional. Ao defender as reformas da ONU, Habermas explica que todas as propostas apresentadas se basearam em prognósticos de erros, mostrando visão objetiva das possibilidades de sucesso, de médio e longo prazo (HABERMAS, 2007, p. 349, 359-360, 363).

Em síntese, as principais propostas de reformas do sistema, veiculadas pelos defensores da ordem cosmopolita, concentram-se em três setas prioritárias: a criação de uma "assembleia parlamentar mundial", não com as mesmas características dos parlamentos nacionais, pois não se pretende constituir um Estado mundial federalista; seus poderes, entretanto, seriam diretos em circunstâncias excepcionais, como as que se relacionam aos direitos fundamentais e às disputas territoriais; envolver as Organizações não Governamentais no debate da assembleia parlamentar, o que, em certa medida, já está sendo feito pela Assembleia Geral; ampliar a interação com as sociedades civis, abrindo canais diretos entre a ONU e os parlamentos nacionais (ARCHIBUGI, 2008, p. 173, 176-177).

Com maior detalhamento, Held divide as mesmas metas em duas categorias: as que podem ser empreendidas a curto prazo e as de longo prazo. Dentre as de curto prazo, ressalta o fortalecimento da participação dos países periféricos no Conselho de Segurança, com a eliminação do sistema de veto; além disso, propõe a criação de uma segunda câmara, nas Nações Unidas, espelhando-se no exemplo europeu, e de uma nova Corte internacional de direitos humanos; Quanto às demais instâncias institucionais, Held defende o estabelecimento da jurisdição compulsória da Corte Internacional de Justiça, bem como o estabelecimento de uma pequena força militar. Por fim, dentre as metas de longo prazo, Held reforça a discutida criação de um parlamento mundial, conectado aos parlamentos regionais e locais, além de defender a elaboração de uma nova Carta de direitos humanos e o estabelecimento de um sistema jurídico global intersectado, incluindo o direito civil e o direito penal, dotado de instrumentos de coação (HELD, 1995, p. 111). ${ }^{8}$

Apesar da importância de todas essas propostas, Habermas lança o alerta no sentido de que as reformas não são o bastante para implementar o projeto do direito cosmopolita; é preciso

8 Sobre as metas da democracia cosmopolita, consulte-se, também, Archibugi (2008, p. 137-155), Falk (1995, p. 170-178) e Habermas (2007, p. 373-381). 
equacionar o problema da legitimação de suas "decisões políticas", ou seja, é preciso dar uma resposta convincente, que afirme seu caráter vinculante, no mesmo patamar de aceitação das decisões estatais; além disso, acrescenta, a questão da legitimação requer uma fundamentação, em dois planos: no supranacional e no transnacional (HABERMAS, 2007, p. 354, 382).

É bom lembrar que a comunidade cosmopolita propugnada por Habermas e os autores, acima citados, dentre outros, configura uma "sociedade mundial sem governo mundial, estruturada politicamente", na qual se circunscreve, de maneira limitada, "a ação dos poderes estatais." Não se trata de marginalizar as competências nacionais, mas, antes, de enquadra-las, em parâmetros compatíveis com a primazia do interesses globais (HABERMAS, 2007, p. 353). Passos estratégicos já foram dados pela experiência da União Europeia, considerada a primeira tentativa de implementar, no plano transnacional, uma "juridificação democrática"; obviamente, a agenda política para o futuro da Europa passou por inúmeros percalços, em sua maioria, provenientes da interferência no debate das questões do mercado, dos bancos e da economia neoliberal, o que termina obscurecendo a dimensão primordial da política (HABERMAS, 2012, p. 4, 40 e 43).

O projeto da União Europeia sempre esteve voltado para o propósito de solidificar um governo continental intervencionista e de superar a concepção da cidadania nacional, a fim de lhe sobrepor o princípio da solidariedade cidadã. Nessa direção, a União Europeia conseguiu estabelecer sua supremacia sobre os interesses dos Estados nacionais que compõem o bloco, estabilizando sua força integrativa (HABERMAS, 2016, p. 117, 119). De outro lado, a partir dos anos 2000, com o crescimento da representatividade dos grupos opositores ao direito comunitário, os chamados "eurocéticos", houve retrocessos. A proposta encaminhada no "Tratado de Lisboa", e submetida a um "referendum", em 2005, para a criação de uma Constituição Europeia, por exemplo, não foi aprovada. O caminho, todavia, encontra-se aberto a novas tentativas, considerando que o Tratado em referência não foi ratificado, à unanimidade, mas o foi por mais da metade dos Estados-Membros. A solidificação de um "espaço público europeu" é fundamental para se adensar o protagonismo da sociedade civil e, portanto, dos cidadãos, propósito tão caro à mundialização do direito. Uma Constituição europeia pode servir de exemplo para o mundo, e dela depende, em nível regional, a afirmação da supremacia do direito comunitário (DELMAS-MARTY, 2007, p. 9-11, 102-103).

Como último comentário sobre o caso da Europa, é oportuno mencionar, pela atualidade, as eleições para um novo mandato no Parlamento Europeu, realizadas no mês de maio de 2019. A eleição contou com a participação de $51 \%$ dos eleitores do continente, a mais alta das duas últimas décadas. Mas o resultado da votação levou à redução, de modo importante, do número de cadeiras ocupadas pelos principais partidos de centro - Aliança Progressista de Socialistas e Democratas (centro esquerda) e Partido Popular Europeu (centro direita) - que apoiam o sistema continental unificado. No mandato atual, os partidos de centro ocupam mais da metade das cadeiras. Com a nova eleição, embora esses mesmos partidos tenham mantido, em conjunto, a maioria dos membros do Parlamento, aumentou o número de representantes dos partidos de extrema direita, os maiores 
combatentes da continuidade do modelo comunitário e defensores do retorno à autonomia total dos Estados. Ressalte-se, por fim, que a representação dos partidos liberais e dos partidos verdes, também, aumentou, significativamente. Os liberais, outra vertente de perfil centrista, advogam posição favorável ao bloco europeu; quanto aos verdes, há divergências entre eles, nesse ponto; o que os unifica, de fato, é, exclusivamente, a bandeira ambientalista. ${ }^{9}$

Voltando à esfera global, é importante reiterar que o maior obstáculo ao direito cosmopolita, como concebido por Kant, reside na escalada do que Habermas denomina "unilateralismo hegemônico", que funciona, praticamente, como uma vertente imperialista recorrente no cenário do direito internacional. Vários são os recuos e omissões de organizações internacionais no esforço de coibir, com sanções, as violações aos direitos humanos, por pressão da potência norte-americana. Habermas chega a dizer que a política do governo estadunidense, na era Bush, ignorou o direito internacional e marginalizou a ONU, além de romper com o diálogo igualitário com a Europa. O autor mostra-se, assim, relativamente pessimista, diante do retrocesso observado nas últimas décadas, em que os Estados Unidos revelou, antes, propósito de estender sua ordem jurídica para a esfera global, ao invés de inserir-se numa ordem internacional pluralista. De nada adianta, alerta-se, "substituir o direito internacional por um ethos particular, pois, em tal caso, tratar-se-ia de direito imperialista, e não direito cosmopolita (HABERMAS, 2016, p. 206-207, 221, 252).

Pierre Bordieu elucida bem esse tipo de estratégia de dominação, a que ele designa como "astúcia da razão imperialista"; o sentido da expressão, para o autor, é o da definição de mecanismos de universalização de particularismos culturais, não por meio de atos de força, mas da manipulação das normas jurídicas. Os próprios intérpretes do direito, no exercício de suas competências, o converte em instrumento de dominação, que funciona como um ato de "violência simbólica". Bordieu explicita a natureza arbitrária, imanente ao funcionamento do direito, comprometedora de sua pressuposta neutralidade, inexistente, em realidade, tendo em vista a adesão dos magistrados, em regra, pertencentes à classe dominante, isto é, à ordem social vigente (BORDIEU, 2014, p. 263, 409, 252-255). No direito internacional, as mesmas estratégias são utilizadas para desviar o desenvolvimento da ideia da democracia cosmopolita, submetendo-a a relações de poder político.

Em rigor, Habermas acredita na capacidade da práxis político-comunicativa de domesticar o "capitalismo desenfreado", contrabalançando o empobrecimento desastroso de "regiões e continentes inteiros." Para tanto, os coautores do diálogo intercontinental precisam eliminar as distorções da argumentação política e o monopólio étnico das culturas hegemônicas (HABERMAS, 2016, p. 41-43). Para Habermas, o direito cosmopolita possui um caráter emancipatório, representando, portanto, a antítese das práticas de dominação e de imposição de interesses das grandes potências sobre os países mais fracos.

\footnotetext{
9 Tudo conforme matéria publicada na BBC News, em 27 de maio de 2019, que traz maiores detalhes no tocante às tendências políticas vitoriosas em cada país; para maior conhecimento do conteúdo da notícia, recomenda-se a consulta ao site da internet: Eleições... (2019).
} 
Na mesma linha de raciocínio, Boaventura Sousa Santos acredita que o direito supranacional pode construir-se como um campo autônomo e homogêneo. Alerta, contudo, que o modelo neoliberal da globalização suprimiu a função emancipatória do direito; por isso, qualquer viés dessa natureza depende de um projeto "contra-hegemônico", gestado por forças sociais periféricas. Grosso modo, o assentimento passivo de sociedades subalternas a condições "supostamente universais" não passa de uma nova roupagem dissimulada dos processos de exclusão, a que Boaventura dá o nome de "localismos globalizados"; propõe, para contrapor-se a essa perspectiva, um cosmopolitismo que surja de contextos sociais oprimidos, ou seja, um "cosmopolitismo subalterno." (SANTOS, 2003, p. $9,13,18)$. Não obstante a distinção metodológica entre Boaventura e Habermas, a quem o primeiro, inclusive, critica pelo fato de focar-se no contexto europeu, que não deixa de representar uma centralidade ocidentalizada, os objetivos de suas teorias é o mesmo; ambas se alinham à construção de um direito internacional não hegemônico.

Linhas gerais, é esse o foco do direito cosmopolita, na visão de Habermas, a idealização normativa de uma sociedade pluralista, de caráter contra-hegemônico, na qual as "sociedades não ocidentais" ocupem o mesmo "espaço de ação", tradicionalmente, ocupado, apenas, pelas sociedades ocidentais. Desse modo, as culturas e saberes do outro lado do mundo, em particular, as dos países empobrecidos, teriam a chance de incorporar as "conquistas da modernidade" utilizando seus "recursos próprios". Em síntese, para vislumbrar alguma perspectiva de realização desse ideal igualitário, não se pode compactuar com uma "sociedade de mercado mundial politicamente desarmada e totalmente desregulamentada." (HABERMAS, 2007, p. 392). Para concluir, recorrendo às palavras de Dellas-Marty, somente a refundação dos poderes, através de um ordenamento jurídico mundial, é capaz de viabilizar a interrupção da dinâmica imperialista e da tendência à rejeição da supranacionalidade institucional.

\section{Considerações finais}

O que há de se destacar na contribuição de Habermas ao tema do Direito Cosmopolita? Primeiro, a adequabilidade do método procedimentalista na análise discursiva do direito internacional, em seu processo de globalização. Com efeito, as normas internacionais de garantia da paz e de proteção aos direitos humanos são robustas, do ponto de vista do seu conteúdo. Todavia, os procedimentos instituídos para conduzir sua aplicação, isto é, a implementação do sistema através da ação dos organismos competentes, não estão levando ao resultado desejado. Isso ocorre devido à ausência de mecanismos eficazes de participação direta da sociedade civil nos respectivos processos decisórios. Ademais, o debate internacional é perpassado pelo enfraquecimento progressivo da instância política, em comparação aos interesses econômicos das superpotências. Nesse contexto, como acredita Habermas, não basta elaborar regras de direito internacional de conteúdo humanitário, pois sua validade depende, também, de procedimentos que assegurem sua concretização. 
Esse estudo mostrou que os fundamentos teóricos do direito cosmopolita são consistentes. Desde suas origens, com o cosmopolitismo moral e político grego, até a doutrina kantiana, que estabeleceu, de forma definitiva, a transposição do enfoque argumentativo para a esfera do direito, a preocupação é a mesma: construir uma comunidade democrática, em nível global, comprometida com a paz, a justiça e a distribuição igualitária dos recursos e benefícios socioeconômicos. Na doutrina contemporânea do cosmopolitismo democrático, a mesma sedimentação categorial foi mantida, chegando-se a um estágio evolutivo importante, que indicou a insuficiência da abordagem kantiana, por restringir-se às relações transnacionais entre os Estados. Em face do protagonismo das visões nacionalistas, a partir da segunda metade do século XX, o projeto do direito cosmopolita direcionouse, com maior ênfase, para a instituição de um modelo de supranacionalidade, no qual a representação da cidadania mundial deixa ser mediatizada pelos Estados. Como se viu, na perspectiva idealizada do direito cosmopolita, é preciso criar órgãos de participação direta dos cidadãos do mundo, bem como de entidades não governamentais, nas organizações internacionais.

O pensamento de Habermas ocupa relevância ímpar no adensamento do direito cosmopolita. Seu paradigma comunicativo da democracia deliberativa oferece uma matriz metodológica adequada para legitimar a ideia da cidadania mundial e a reformulação da esfera da soberania dos Estados. Como se explicitou, o sistema do direito, em todos os níveis, segundo Habermas, deve estar comprometido com o constitucionalismo republicano, que unifica, em sua substância, a autonomia pública e a autonomia privada. Nessa leitura, restou demonstrado que o protagonismo dos direitos humanos se associa à estruturação do projeto cosmopolita, abrindo o caminho para o aperfeiçoamento normativo do direito internacional.

Por fim, entende-se ter se alcançado o objetivo de expor o panorama dos passos já percorridos, e do longo percurso, ainda, a ser pavimentado, em prol da concretização do direito cosmopolita. Viu-se que, sem o estabelecimento de um controle vinculante, por parte dos Órgãos de decisão do direito internacional, no que concerne ao cumprimento dos tratados e outras espécies de documentos, ou acordos, no nível dos poderes estatais, não se avançará no progresso do projeto cosmopolita. $\bigcirc$ foco das propostas de inovação institucional concentra-se nas reformas da ONU, com destaque para o aumento da participação direta dos cidadãos do mundo nos processos de tomada de decisão. Além disso, sem o fortalecimento de outras medidas, que reduzam a interferência hegemônica das superpotências nas diretrizes dos colegiados, propiciando tratamento igualitário aos interesses de todos os povos, não se sairá, igualmente, do estágio insatisfatório no qual se encontra, hoje, a receptividade do direito supranacional na consciência das autoridades públicas dos Estados.

\section{REFERÊNCIAS}

ARAÚJO, Cícero Romão Resende. A forma da república: da constituição mista ao Estado. São Paulo: Martins Fontes, 2013. 
ARCHIBUGI, Daniele. The global commonwealth of citizens: toward cosmopolitan democracy. New Jersey, Oxford: Princeton University Press, 2008.

AUSTIN, John. How to do things with words. New York: New York Press, 1965.

BENHABIB, Seyla. Another cosmopolitanism. Oxford: Oxford University Press, 2006.

BUNCHAFT, Maria Eugênia. Patriotismo Constitucional: Jürgen Habermas e a reconstrução da ideia de Nação na Filosofia Política contemporânea. Curitiba: Juruá, 2015.

CID, Isabel Victória Lucena. Los principios cosmopolitas y la justicia global. Isegoría, Revista de Filosofia Moral y Política,[S. l.], n. 44, p. 185-201, enero/jun. 2011. Disponível em: https://doi. org/10.3989/isegoria.2011.i44.725. Acesso em: 30 maio 2019.

DELEIXHE, Martin. Re-Evaluating Kant's Cosmopolitan Law: european citizenship as a transition from the right to visitation to the right to residence. Revue Française de Science Politique/English, [S. l.], v. 64, n. 1, p. 79-93, 2014. Disponível em: https://www.cairn.info/ article-E_RFSP_641_ 0079--re-evaluating-kant-s-cosmopolitanlaw.htm. Acesso em: 30 maio 2019.

DELMAS-MARTY, Mireille. Les forces imaginaires du droit (III): La Refondation des Povoirs. Paris: Seuil, 2007.

ELEIÇÕES PARA PARLAMENTO EUROPEU: QUEM SÃO OS GANHADORES E PERDEDORES E O QUE ISSO REPRESENTA. BBC News, 27 maio 2019. Disponível em: https://www.bbc.com/ portuguese/internacional-48420794. Acesso em: 30 maio 2019.

FALK, Richard. The world order between Inter-State Law and the Law of Humanity: the role of civil society institutions. In: ARCHIBUGI, Daniele; HELD, David. Cosmopolitan Democracy: An Agenda for a New World Order. Cambridge: Polity Press, 1995.

HABERMAS, Jürgen. A Constelação Pós-Nacional: ensaios políticos. São Paulo: Littera Mundi, 2001.

HABERMAS, Jürgen. A nova obscuridade: pequenos escritos políticos V. São Paulo: Ed. Unesp, 2015.

HABERMAS, Jürgen. Direito e democracia: entre facticidade e validade. Rio de Janeiro: Tempo Brasileiro, 2010. v. 2.

HABERMAS, Jürgen. Entre naturalismo e religião: estudos filosóficos. Rio de Janeiro: Tempo Brasileiro, 2007.

HABERMAS, Jürgen. Era das transições. Rio de Janeiro: Tempo Brasileiro, 2003.

HABERMAS, Jürgen. La logica de las ciencias sociales. Madri: Editorial Tecnos, S.A., 1988. ISBN: 84309-1561-3.

HABERMAS, Jürgen. Moral consciousness and communicative action. Cambridge, Massachusetts: The MIT Press, 1990.

HABERMAS, Jürgen. O ocidente dividido: pequenos escritos políticos. São Paulo: Ed. Unesp, 2016.

HABERMAS, Jürgen. Sobre a Constituição da Europa. São Paulo: Ed. Unesp, 2012. 
HABERMAS, Jürgen. The inclusion of the other: studies in political theory. Cambridge, Massachusetts: Massachusetts Institute of Technology, 1998.

HABERMAS, Jürgen. Théorie de l'agir communicationnel. Paris: Fayard, 1987.

HALL, Stuart. A Identidade cultural na pós-modernidade. 7. ed. Rio de Janeiro: DP\&A Editora, 2002.

HELD, David. A democracia, o Estado-Nação e o sistema gobal. Lua Nova: Revista de Cultura e Política, São Paulo, n. 23, p. 145-194, mar. 1991. Disponível em: www.scielo.br. Acesso em: 30 maio 2019.

HELD, David. Democracy and the new international order. In: ARCHIBUGI, Daniele; HELD, David Cosmopolitan Democracy: An Agenda for a New World Order. Cambridge: Polity Press, 1995.

KANT, Immanuel. A paz perpétua. In: KANT, Immanuel. A paz perpétua e outros opúsculos. Lisboa: Edições 70, 1988a.

KANT, Immanuel. Crítica da Razão Prática. Lisboa: Edições 70, 1989.

KANT, Immanuel. Fundamentação da Metafísica dos Costumes. São Paulo: Barcarolla, 2009.

KANT, Immanuel. Ideia de uma história universal com um propósito cosmopolita. In: KANT, Immanuel. A paz perpétua e outros opúsculos. Lisboa: Edições 70, $1988 \mathrm{~b}$.

KELSEN, Hans; CAMPAGNOLO, Umberto. Direito Internacional e Estado soberano. São Paulo: Martins Fontes, 2002.

LACROIX, Justine. Patriotismo constitucional e identidade pós-nacional em Jürgen Habermas. In: ROCHLITZ, Rainer. Habermas: o uso público da razão. Rio de Janeiro: Tempo Brasileiro, 2005.

MENEZES, Rodrigo Ramos Lourega de. O direito de visita a território estrangeiro à luz do Direito Cosmopolita. Ijuí: Ed. UniJuí, 2017. v. 2.

OLIVEIRA, Juliano Cordeiro da Costa. Entre o liberalismo e o republicanismo: Habermas e a democracia deliberativa. Revista Dialectus, [S. l.], ano 4, n. 11, p. 280-296, ago./dez. 2017. Disponível em: www.periodicos.ufc.br/dialectus/article/download/31014/71638. Acesso em: 30 maio 2019.

PIRES, Teresinha Inês Teles. O Primado da Razão Prática em Kant. Porto Alegre: Nuria Fabris, 2012.

SANTOS, Boaventura Sousa. Poderá o direito ser emancipatório? Revista Crítica de Ciências Sociais, [S. l.], n. 65, p. 3-76, 2003, Disponível em: http://www.boaventuradesousasantos.pt/media/ pdfs/ podera_o_direito_ser_emancipatorio_RCCS65.PDF. Acesso em: 30 maio 2019. 